\title{
CLINICAL ASSESSMENT OF ELECTROMAGNETIC COMPATIBILITY OF HEARING AIDS AND DIGITAL WIRELESS PHONES
}

\author{
Robert E. Schlegel, Shalini Srinivasan, Hank Grant, Randa L. Shehab, Shivakumar Raman \\ School of Industrial Engineering, University of Oklahoma \\ Norman, OK 73019
}

\begin{abstract}
Research studies have shown that digital wireless phones interact with some hearing aids, creating a buzzing noise that may reduce speech intelligibility. Interference signals for three phone technologies were generated at five sound pressure levels $(35 \mathrm{~dB}, 45 \mathrm{~dB}, 55 \mathrm{~dB}, 65 \mathrm{~dB}$, and $75 \mathrm{~dB}$ ) and mixed with speech at $65 \mathrm{~dB}$ SPL to test the speech intelligibility of 24 hearing-impaired people. A "No Noise" condition was also tested. Scores for the TDMA$217 \mathrm{~Hz}$ phone signal at low speech-to-noise ratios $(<10 \mathrm{~dB})$ were significantly lower than those for CDMA and TDMA-50 Hz at the same level. The CDMA and TDMA-50 Hz phone signals had a similar effect on speech intelligibility. Speech intelligibility scores at speech-tonoise ratios of $20 \mathrm{~dB}$ and $30 \mathrm{~dB}$ were similar to those for the "No Noise" condition. The articulation index represented the best index for predicting the impact of wireless phone interference on speech intelligibility.
\end{abstract}

\section{INTRODUCTION}

The use of wireless phones is becoming more widespread, with more than 50 million in use in the United States today. Approximately $10 \%$ of the currently existing wireless phones in the United States operate in a digital mode, and many of these operate in both analog and digital modes. One of the many advantages of a digital phone system is the possibility of increasing the number of users within a frequency band through multiplexing. However, digital wireless phones interact with some hearing aids creating a buzzing noise that reduces speech intelligibility for some hearing-impaired individuals. Research studies have been conducted by the National Acoustic Laboratories (NAL; Australia), the European Hearing Instrument Manufacturers Association (EHIMA; Europe), and the Center for the Study of Wireless Electromagnetic Compatibility at the University of Oklahoma (OU EMC; USA) to investigate the extent of this audio interference and its effect on speech intelligibility. The University of Oklahoma Center for the Study of Wireless Electromagnetic Compatibility (EMC) initiated a program of research in May 1995 to determine the potential for interaction between wireless phones and hearing aids, to evaluate the effectiveness of proposed solutions to mitigate negative interactions, and to develop test methods and criteria leading to EMC design standards for hearing aids and digital wireless devices.

Phone technologies and digital signal structures vary internationally according to (1) the carrier frequency, (2) the type of multiple access technique, and (3) the pulse repetition frequency of the RF bursts. Digital phones multiplex among different users by transmitting the radio frequency (RF) carrier signal in short bursts with fixed on and off time intervals. When these phones are placed in close proximity to audio devices such as hearing aids and audio cassette players, the RF carrier signal may be picked up in the electronic circuitry of these products. The waveform envelope of the RF bursts is then demodulated in the amplifier circuit. The resulting signal is a square wave with the same frequency and duty cycle as the RF bursts. This signal, when output to a speaker, is heard as a buzzing or static noise that reduces the intelligibility of speech. Time Division Multiple Access (TDMA) and Code Division Multiple Access (CDMA) are two multiplexing schemes used for digital phones. TDMA-50 Hz, TDMA-217 Hz, and CDMA phones exist at both the low frequency (800-900 $\mathrm{MHz}$ ) and high frequency bands (1800-1900 MHz). Depending on the technology and the standard in a particular country, the maximum output power of the phones varies from $600 \mathrm{~mW}$ to $2 \mathrm{~W}$.

Figure 1 depicts the overall multi-phase hearing aid EMC research program at the University of Oklahoma. The Phase I Clinical Study focused on testing 68 hearing aid wearers and 10 people with unimpaired hearing to (1) evaluate the degree of interaction between wireless phones and hearing aids, (2) document the existence and severity of the interaction as a function of hearing aid type, hearing loss characteristics, and wireless phone technology, 


\section{Wireless Phone}

\section{Hearing Aids}
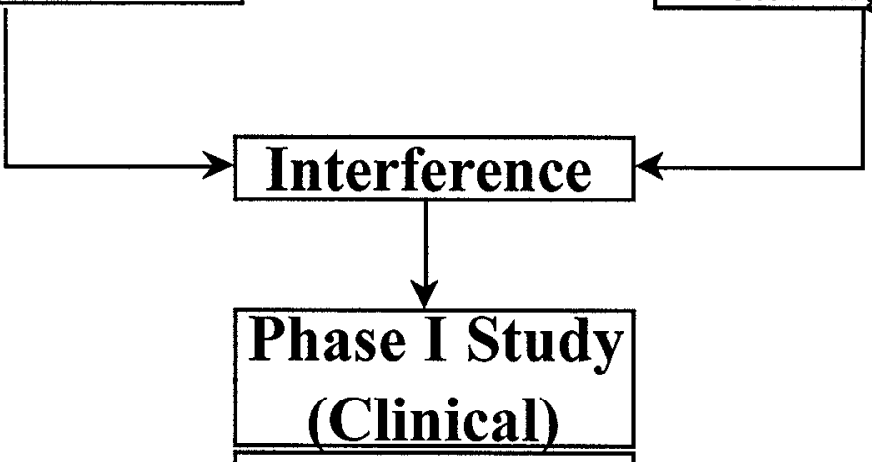

Characterize interference

Effectiveness of solutions

\section{Outputs}

Speech intelligibility

Detection threshold

Annoyance rating

\begin{tabular}{|c|c|c|}
\hline \multicolumn{3}{|c|}{ Phase II Study (Laboratory/Clinical) } \\
\hline $\begin{array}{l}\text { Phase I-A } \\
\text { (Repeatable Testing Procedure) }\end{array}$ & $\begin{array}{r}\text { Phase I-B } \\
\text { (Clinical Study) }\end{array}$ & $\begin{array}{c}\text { Phase II-C } \\
\text { (Waveguide Testing) }\end{array}$ \\
\hline $\begin{array}{l}\text {-Quantify interference } \\
\text {-Develop noise-free, repeatable } \\
\text { experimentation setup }\end{array}$ & $\begin{array}{l}\text {-Quantify signal/noise } \\
\text {-Standards development } \\
\text { and labeling }\end{array}$ & $\begin{array}{l}\text {-Use NAL waveguide } \\
\text {-Verify NAL results } \\
\text {-Use actual phones }\end{array}$ \\
\hline \multicolumn{3}{|c|}{ Outputs } \\
\hline $\begin{array}{l}\text {-Input Referred } \\
\text { Interference Spectrum (IRIS) } \\
\text {-Effects of tubing, setup, } \\
\text { components, and repeatability }\end{array}$ & $\begin{array}{l}\text {-Signal/Noise characteristics } \\
\text {-Speech intelligibility } \\
\text {-Annoyance rating }\end{array}$ & $\begin{array}{l}\cdot \text { ILM } 40,55,60 \\
\cdot \text { Effects of different } \\
\text { transmit frequency }\end{array}$ \\
\hline
\end{tabular}

Figure 1. Hearing Aid - Wireless Phone Interaction Study.

and (3) determine the effectiveness of solutions such as shielding the hearing aid and shielding the phone antenna.. An EMC Center report documents the study (Ravindran et al., 1996), which is summarized in Ravindran et al. (1997).

The Phase I Clinical Study demonstrated the complexity of the hearing aid-wireless phone interaction while confirming that bystander interference to a hearing aid wearer was of less concern than user interference. Therefore, Phase II research efforts were directed toward the effective use of the wireless digital phone by a hearing aid user.
Phase II involved acoustic measurements and clinical testing, and comprised three parallel studies. Phase II$A$ involved acoustic measurements of hearing aids within a sound-isolation chamber. Phase II-B examined speech-to-interference ratios in an attempt to determine a range of values allowing effective use of digital phones by hearing aid wearers. Phase II-C focused on the use of the Australian Hearing Services National Acoustic Laboratories (NAL) waveguide to measure the radio frequency (RF) immunity of a number of hearing aids. All of the Phase II work forms a major contribution to the efforts of the ANSI 
Accredited Standards Committee C63.19 to develop standards for methods of measurement and performance criteria for phone emissions and hearing aid immunity. The results of the Phase II-B study are reported here.

One factor that determines effective speech communication is the speech-to-noise ratio ("speechto-buzz" or signal-to-noise ratio; $\mathrm{S} / \mathrm{N}$ ratio). The speech-to-noise ratio is the numerical difference between the overall root mean square (RMS) levels of the speech and noise. EHIMA (1995) has established $55 \mathrm{~dB}$ (linear weighted sound pressure level) as the upper limit of interference to guarantee acceptable intelligibility of speech for hearing aid interaction with GSM phones (S/N of $10 \mathrm{~dB}$ assuming $65 \mathrm{~dB}$ for speech at $1 \mathrm{~m}$ from a live talker). Hansen and Poulsen (1995) reported a $\mathrm{S} / \mathrm{N}$ ratio of $20 \mathrm{~dB}$ as an acceptable level for hearing aid interaction with GSM and DECT phones.

To date, there have been no published results on an acceptable S/N ratio for TDMA $-50 \mathrm{~Hz}$ or CDMA phones. There are also no published results comparing the effect of different speech-to-buzz ratios on speech intelligibility. The objectives of the research reported here were as follows:

1. Compare the effect of different phone signal formats on speech intelligibility and annoyance.

2. Identify the relationship between interference level and speech intelligibility for a fixed speech level of $65 \mathrm{~dB}$ SPL.

3. Compare different sound weighting schemes (Linear Weighting, A-weighting, and Cweighting) and predictive indices of speech intelligibility (Speech Interference Level and Articulation Index) to determine the best measure representing the impact of noise spectral content on the recognition of speech.

\section{METHOD}

To devclop a standard interference signal that could be used to test all hearing aids, hearing aid output interference was converted to an equivalent acoustic input referenced interference spectrum (IRIS). Interference signals for three phone technologies (CDMA, TDMA-50 Hz, and TDMA-217 Hz) were generated at five sound pressure levels $(35 \mathrm{~dB}, 45 \mathrm{~dB}$, $55 \mathrm{~dB}, 65 \mathrm{~dB}$, and $75 \mathrm{~dB}$ ) and mixed with speech at 65 $\mathrm{dB}$ SPL to test the speech intelligibility of 24 hearingimpaired people. A "No Noise" condition was also tested. Annoyance ratings (short-term annoyance before, long-term annoyance during and short-term annoyance after speech intelligibility testing) were also collected for each test condition using a 0 to 5 scale ( 0 -no interference to 5 -unbearable).

\section{RESULTS}

Table 1 presents the speech intelligibility scores and annoyance ratings for all combinations of phone technology and interference noise level. Speech intelligibility scores for the TDMA-217 $\mathrm{Hz}$ IRIS phone signal at low speech-to-noise ratios $(<10 \mathrm{~dB})$ were significantly lower than those for CDMA and TDMA-50 Hz at the same level. The CDMA and TDMA-50 Hz IRIS phone signals had a similar effect on speech intelligibility. For all three phone technologies, speech intelligibility scores at speech-tonoise ratios of $20 \mathrm{~dB}$ and $30 \mathrm{~dB}$ were not statistically different from those for the "No Noise" condition.

Annoyance ratings increased as a function of noise level. Long-term annoyance ratings collected during speech intelligibility testing were higher than the short-term annoyance ratings collected before and after speech intelligibility testing. Short-term annoyance ratings increased following long-term exposure to noise. Ninety percent of the participants reported annoyance between "No Interference" and "Not Annoying" for annoyance ratings collected during speech intelligibility testing at $35 \mathrm{~dB}$ SPL(L).

To determine the best index for representing the relationship between the noise spectrum and speech intelligibility, different weighting schemes (linear weighting, A-weighting, C-weighting, speech interference level, and articulation index) were applied to the IRIS signal from the three phone technologies. Since the IRIS levels were established as linearweighted levels, but the relationship between overall SPL(L) and speech intelligibility differed among the phone technologies, it can be concluded that the linear weighting does not aptly predict speech intelligibility. Among the other weighting schemes, C-weighting was similar to the linear weighting scheme and was also not a suitable measure. Although A-weighted interference levels were considerably different from the linear-weighted or C-weighted levels, the Aweighting scheme did not improve the predictability of speech intelligibility.

The three-band speech interference level (SIL) was calculated for each IRIS signal. Among the three phone technologies, the SIL for TDMA-217 Hz was higher than for the CDMA and TDMA-50 Hz signals, and aptly predicted the lower speech intelligibility scores for TDMA-217 Hz compared to CDMA and TDMA-50 $\mathrm{Hz}$ at the same overall level. Speech intelligibility was found to have a clear inverse monotonic relationship with SIL. However, the frequencies used for calculation of the three-band SIL range from 355 to $2800 \mathrm{~Hz}$, and thus SIL may not appropriately represent noise spectra with highfrequency components. 
Table 1. Summary Table of Means (Standard Deviations) of Dependent Measures.

\begin{tabular}{|c|c|c|c|c|c|c|c|c|}
\hline \multirow[b]{2}{*}{$\begin{array}{c}\text { Phone } \\
\text { Technology }\end{array}$} & \multirow[b]{2}{*}{$\begin{array}{l}\text { Dependent } \\
\text { Measure }\end{array}$} & \multicolumn{7}{|c|}{ Noise Level (dB SPL) } \\
\hline & & $\begin{array}{c}\text { No } \\
\text { Noise } \\
\end{array}$ & $\begin{array}{c}35 \\
S / N=30\end{array}$ & $\begin{array}{c}45 \\
S / N=20\end{array}$ & $\begin{array}{c}55 \\
\mathrm{~S} / \mathrm{N}=10\end{array}$ & $\begin{array}{c}65 \\
\mathrm{~S} / \mathrm{N}=0 \\
\end{array}$ & $\begin{array}{c}75 \\
S / N=-10\end{array}$ & $\begin{array}{c}\text { Summary } \\
*\end{array}$ \\
\hline \multirow[t]{4}{*}{ CDMA } & $\begin{array}{c}\text { Speech Intell. } \\
(\%)\end{array}$ & $\begin{array}{c}76.3 \\
(18.3)\end{array}$ & $\begin{array}{c}73.0 \\
(18.3)\end{array}$ & $\begin{array}{c}75.7 \\
(15.6)\end{array}$ & $\begin{array}{c}70.2 \\
(17.3)\end{array}$ & $\begin{array}{c}59.8 \\
(15.5)\end{array}$ & $\begin{array}{c}28.5 \\
(16.3)\end{array}$ & $\begin{array}{c}61.4 \\
(16.6)\end{array}$ \\
\hline & $\begin{array}{c}\text { Annoyance } \\
\text { (before) }\end{array}$ & $\begin{array}{c}0.0 \\
(0.0) \\
0 . \cdots\end{array}$ & $\begin{array}{c}0.0 \\
(0.0)\end{array}$ & $\begin{array}{c}0.5 \\
(0.5) \\
0.1\end{array}$ & $\begin{array}{c}1.1 \\
(0.6) \\
\end{array}$ & $\begin{array}{c}2.2 \\
(1.0) \\
(1.0)\end{array}$ & $\begin{array}{c}3.2 \\
(1.0)\end{array}$ & $\begin{array}{c}1.4 \\
(0.6)\end{array}$ \\
\hline & $\begin{array}{c}\text { Annoyance } \\
\text { (during) }\end{array}$ & $\begin{array}{c}0.0 \\
(0.0)\end{array}$ & $\begin{array}{c}0.1 \\
(0.3)\end{array}$ & $\begin{array}{c}0.9 \\
(0.8)\end{array}$ & $\begin{array}{c}1.7 \\
(1.0)\end{array}$ & $\begin{array}{c}2.9 \\
(0.9)\end{array}$ & $\begin{array}{c}3.9 \\
(0.9)\end{array}$ & $\begin{array}{c}1.9 \\
(0.8)\end{array}$ \\
\hline & $\begin{array}{l}\text { Annoyance } \\
\text { (after) }\end{array}$ & $\begin{array}{c}0.0 \\
(0.0) \\
\end{array}$ & $\begin{array}{c}0.1 \\
(0.3) \\
\end{array}$ & $\begin{array}{c}0.8 \\
(0.8) \\
\end{array}$ & $\begin{array}{c}1.4 \\
(0.8) \\
\end{array}$ & $\begin{array}{c}2.7 \\
(0.9)\end{array}$ & $\begin{array}{c}3.8 \\
(0.9)\end{array}$ & $\begin{array}{c}1.8 \\
(0.9)\end{array}$ \\
\hline \multirow[t]{4}{*}{$\begin{array}{c}\text { TDMA } \\
50 \mathrm{~Hz}\end{array}$} & $\begin{array}{c}\text { Speech Intell. } \\
(\%)\end{array}$ & $\begin{array}{c}76.3 \\
(18.3)\end{array}$ & $\begin{array}{c}73.2 \\
(19.8) \\
.19 .8\end{array}$ & $\begin{array}{c}73.3 \\
(14.5) \\
\end{array}$ & $\begin{array}{c}66.0 \\
(17.7) \\
\end{array}$ & $\begin{array}{c}60.7 \\
(17.9)\end{array}$ & $\begin{array}{c}37.0 \\
(20.8) \\
(20.0\end{array}$ & $\begin{array}{c}62.0 \\
(18.1)\end{array}$ \\
\hline & $\begin{array}{l}\text { Annoyance } \\
\text { (before) }\end{array}$ & $\begin{array}{c}0.0 \\
(0.0)\end{array}$ & $\begin{array}{c}0.0 \\
(0.0)\end{array}$ & $\begin{array}{c}0.5 \\
(0.5)\end{array}$ & $\begin{array}{c}1.3 \\
(0.6)\end{array}$ & $\begin{array}{c}2.4 \\
(1.0)\end{array}$ & $\begin{array}{c}3.7 \\
(1.0)\end{array}$ & $\begin{array}{c}1.6 \\
(0.6)\end{array}$ \\
\hline & $\begin{array}{l}\text { Annoyance } \\
\text { (during) }\end{array}$ & $\begin{array}{c}0.0 \\
(0.0)\end{array}$ & $\begin{array}{c}0.2 \\
(0.4)\end{array}$ & $\begin{array}{c}0.6 \\
(0.7)\end{array}$ & $\begin{array}{c}2.2 \\
(0.9)\end{array}$ & $\begin{array}{c}3.3 \\
(0.9)\end{array}$ & $\begin{array}{c}4.3 \\
(0.7)\end{array}$ & $\begin{array}{c}2.1 \\
(0.7)\end{array}$ \\
\hline & $\begin{array}{l}\text { Annoyance } \\
\text { (after) }\end{array}$ & $\begin{array}{c}0.0 \\
(0.0) \\
\end{array}$ & $\begin{array}{c}0.0 \\
(0.2) \\
\end{array}$ & $\begin{array}{c}0.7 \\
(0.6) \\
\end{array}$ & $\begin{array}{c}1.7 \\
(0.8) \\
\end{array}$ & $\begin{array}{c}2.7 \\
(0.7) \\
\end{array}$ & $\begin{array}{c}4.2 \\
(0.8) \\
\end{array}$ & $\begin{array}{c}1.9 \\
(0.6) \\
\end{array}$ \\
\hline \multirow[t]{4}{*}{$\begin{array}{l}\text { TDMA } \\
217 \mathrm{~Hz}\end{array}$} & $\begin{array}{c}\text { Speech Intell. } \\
(\%)\end{array}$ & $\begin{array}{c}76.3 \\
(18.3) \\
\ldots\end{array}$ & $\begin{array}{c}72.0 \\
(16.8)\end{array}$ & $\begin{array}{c}70.7 \\
(16.6) \\
\end{array}$ & $\begin{array}{c}64.0 \\
(19.3) \\
\end{array}$ & $\begin{array}{c}49.2 \\
(20.6)\end{array}$ & $\begin{array}{c}9.4 \\
(10.3) \\
. \cdots\end{array}$ & $\begin{array}{c}53.1 \\
(16.7)\end{array}$ \\
\hline & $\begin{array}{c}\text { Annoyance } \\
\text { (before) }\end{array}$ & $\begin{array}{c}0.0 \\
(0.0)\end{array}$ & $\begin{array}{c}0.1 \\
(0.3)\end{array}$ & $\begin{array}{c}0.9 \\
(0.7) \\
\end{array}$ & $\begin{array}{c}1.9 \\
(0.8)\end{array}$ & $\begin{array}{c}2.9 \\
(1.1)\end{array}$ & $\begin{array}{c}3.6 \\
(1.1)\end{array}$ & $\begin{array}{c}1.9 \\
(0.8)\end{array}$ \\
\hline & $\begin{array}{l}\text { Annoyance } \\
\text { (during) }\end{array}$ & $\begin{array}{c}0.0 \\
(0.0)\end{array}$ & $\begin{array}{c}0.2 \\
(0.5)\end{array}$ & $\begin{array}{c}1.2 \\
(0.9)\end{array}$ & $\begin{array}{c}2.9 \\
(0.9)\end{array}$ & $\begin{array}{c}4.0 \\
(0.7)\end{array}$ & $\begin{array}{c}4.5 \\
(0.7)\end{array}$ & $\begin{array}{c}2.6 \\
(0.7)\end{array}$ \\
\hline & $\begin{array}{l}\text { Annoyance } \\
\text { (after) }\end{array}$ & $\begin{array}{c}0.0 \\
(0.0) \\
\end{array}$ & $\begin{array}{c}0.1 \\
(0.3)\end{array}$ & $\begin{array}{c}1.3 \\
(0.7) \\
\end{array}$ & $\begin{array}{r}2.5 \\
(0.9) \\
\end{array}$ & $\begin{array}{r}3.3 \\
(1.1) \\
\end{array}$ & $\begin{array}{c}4.1 \\
(0.7) \\
\end{array}$ & $\begin{array}{c}2.3 \\
(0.7) \\
\end{array}$ \\
\hline \multirow[t]{4}{*}{ Summary } & $\begin{array}{c}\text { Speech Intell. } \\
(\%)\end{array}$ & $\begin{array}{c}76.3 \\
(18.3) \\
\end{array}$ & $\begin{array}{c}72.7 \\
(18.3) \\
(13.3)\end{array}$ & $\begin{array}{c}73.2 \\
(15.6) \\
(13.6\end{array}$ & $\begin{array}{c}66.7 \\
(18.1)\end{array}$ & $\begin{array}{c}56.6 \\
(18.0) \\
(13 . .1\end{array}$ & $\begin{array}{c}24.9 \\
(15.8)\end{array}$ & \\
\hline & $\begin{array}{c}\text { Annoyance } \\
\text { (before) }\end{array}$ & $\begin{array}{c}0.0 \\
(0.0)\end{array}$ & $\begin{array}{c}0.1 \\
(0.1) \\
. .1 .\end{array}$ & $\begin{array}{c}0.6 \\
(0.6)\end{array}$ & $\begin{array}{c}1.4 \\
(0.6)\end{array}$ & $\begin{array}{c}2.5 \\
(1.0)\end{array}$ & $\begin{array}{c}3.5 \\
(1.0)\end{array}$ & \\
\hline & $\begin{array}{l}\text { Annoyance } \\
\text { (during) }\end{array}$ & $\begin{array}{c}0.0 \\
(0.0)\end{array}$ & $\begin{array}{c}0.2 \\
(0.4)\end{array}$ & $\begin{array}{c}0.9 \\
(0.8)\end{array}$ & $\begin{array}{c}2.3 \\
(0.9)\end{array}$ & $\begin{array}{c}3.4 \\
(0.8)\end{array}$ & $\begin{array}{c}4.2 \\
(0.8)\end{array}$ & \\
\hline & $\begin{array}{c}\text { Annoyance } \\
\text { (after) }\end{array}$ & $\begin{array}{c}0.0 \\
(0.0)\end{array}$ & $\begin{array}{c}0.1 \\
(0.3)\end{array}$ & $\begin{array}{r}0.9 \\
(0.7) \\
\end{array}$ & $\begin{array}{r}1.9 \\
(0.8) \\
\end{array}$ & $\begin{array}{r}2.9 \\
(0.9) \\
\end{array}$ & $\begin{array}{r}4.0 \\
(0.8) \\
\end{array}$ & \\
\hline
\end{tabular}

* Does not include "No Noise" condition.

The articulation index (AI) was calculated for each of the three IRIS phone signals. The AI scores also had a clear increasing monotonic relationship with the absolute speech intelligibility scores. Figure 2 presents speech intelligibility as a function of Al for each combination of phone technology and interference level. For AI scores below 0.3, the speech intelligibility decreased to $50 \%$ of the "No Noise" baseline condition. For AI scores higher than 0.9 , the speech intelligibility scores were similar to those for the "No Noise" condition.

\section{DISCUSSION}

The effects of the three phone signals, CDMA, TDMA-50 Hz, and TDMA-217 Hz, on speech intelligibility and annoyance at different interference levels vary depending on the spectral pattern of the interference, which in turn depends on the RF pulse repetition frequency. Among the three phone signal formats, TDMA-217 Hz with a fundamental frequency of $217 \mathrm{~Hz}$ produced the lowest average speech intelligibility. 


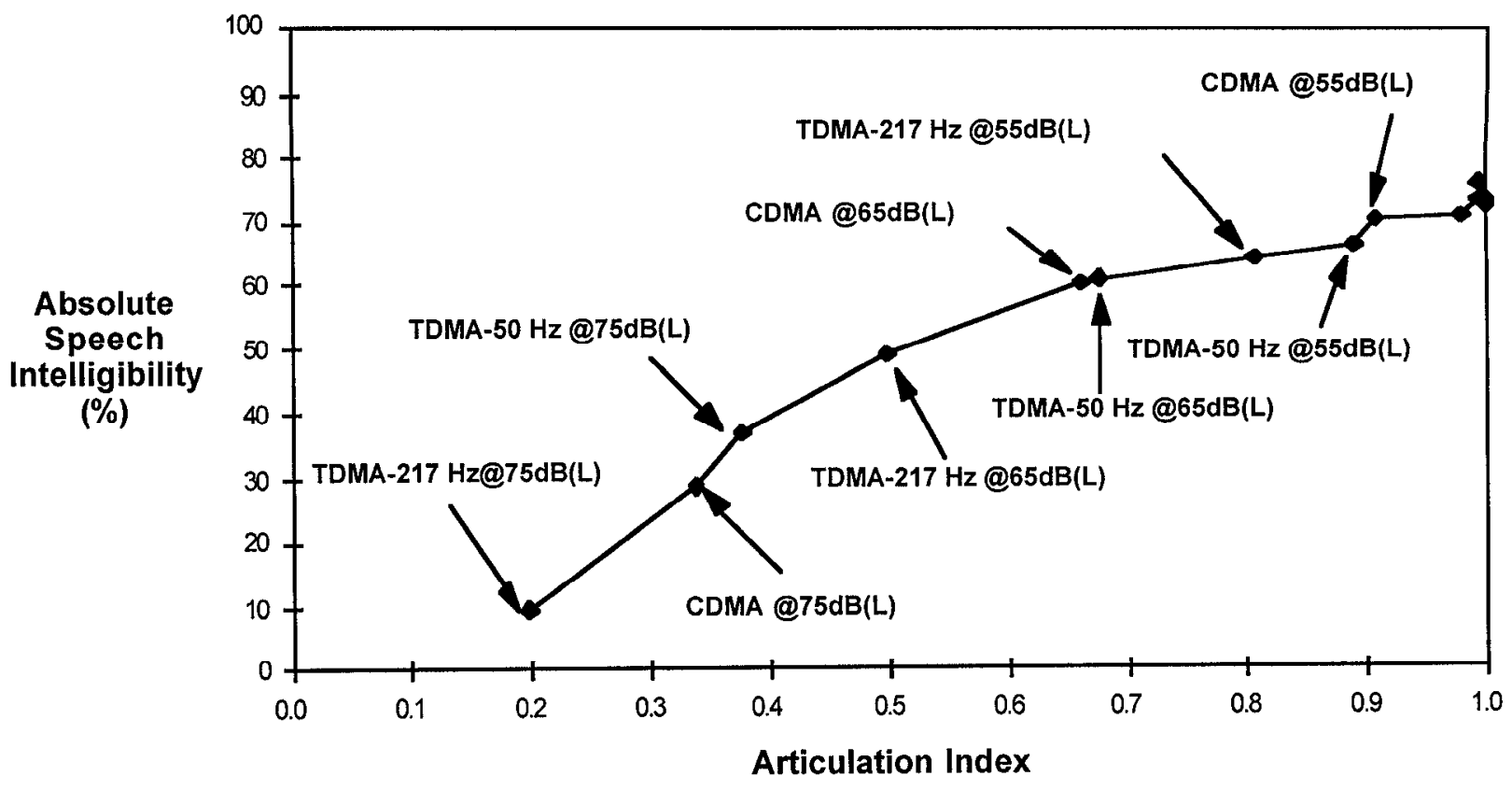

Figure 2. Average Speech Intelligibility Score (\%) vs. Articulation Index for All Phone Technologies.

The TDMA-217 $\mathrm{Hz}$ signal also had the highest average annoyance rating for all three occasions. CDMA and TDMA-50 Hz had similar average shortterm annoyance ratings after speech intelligibility. However, the average annoyance rating before and during speech intelligibility was significantly higher for the TDMA-50 Hz signal than for the CDMA signal. For all three phone technologies, ratings were higher for long-term annoyance during speech intelligibility than for short-term annoyance either before or after the speech intelligibility testing. Likewise, for all three phone technologies, the average short-term annoyance rating after speech intelligibility was higher than the average short-term annoyance rating before speech intelligibility. Thus, long-term exposure to noise increased the annoyance rating regardless of the type of noise, and the prior long-term exposure to noise also resulted in higher short-term annoyance ratings.

Based on the results of speech intelligibility and annoyance rating, it can be concluded that at an interference level of $35 \mathrm{~dB}$ SPL (L), speech intelligibility and the annoyance ratings are not statistically different from the "No Noise" condition. Therefore, $35 \mathrm{~dB}$ SPL can be considered as an acceptable interference level (i.e., a $30 \mathrm{~dB} \mathrm{~S} / \mathrm{N}$ ratio can be considered acceptable for effective speech communication instead of the $55 \mathrm{~dB}$ SPL recommended by the EHIMA study). Moreover, the effect of the interference varies with its spectral content.
Among the various weighting schemes, both SIL and AI were found to have a good correlation with speech intelligibility. However, SIL uses a more limited frequency range. Therefore, from the results of this research, AI is recommended as the single index to best represent the impact of wireless phone interference on speech intelligibility, irrespective of the type of IRIS phone signal.

\section{REFERENCES}

European Hearing Instrument Manufacturers Association (EHIMA; 1995). Hearing aids and GSM mobile telephones: Interference problems, methods of measurement, and levels of immunity, EHIMA GSM Project Final Report 1995-11-01. Delta Acoustics \& Vibration and Telecom Denmark.

Hansen, H.O., and Poulsen, T. (1995). Evaluation of noise in hearing aids caused by GSM and DECT. A Masters Thesis. The Acoustics Laboratory, The Technical University of Denmark. (Referenced from Appendix B of EHIMA, 1995).

Le Strange, J.R., Byrne, D., Joyner, K.H., and Symons, G.L. (1995). Interference to hearing aids by the digital mobile telephone system, Global System for Mobile communications (GSM). NAL Report No. 131. Chatswood, New South Wales, Australia: National Acoustic Laboratories, Australian Hearing Services.

Ravindran, A., Schlegel, R.E., and Grant, H. (1996). Evaluation of the interaction between wireless phones and hearing aids, Phase I: Results of the clinical trials. Norman, OK: Center for the Study of Wireless Electromagnetic Compatibility, University of Oklahoma.

Ravindran, A., Schlegel, R.E., Grant, H., Matthews, P., and Scates, P. (1997). Study measures interference to hearing aids from digital phones. The Hearing Journal, 50, 32-34. 